\title{
Correlation of religiosity and emotional intelligence among students of Madrasah Aliyah Denpasar
}

\author{
Endy Nurhayati', \\ Cokorda Bagus Jaya \\ Lesmana², \\ Luh Nyoman Alit Aryani²
}

'Department of Psychiatry, Hermina Tangkuban Perahu Hospital, East Java, Indonesia

${ }^{2}$ Department of Psychiatry, Faculty of Medicine, Udayana University, Bali, Indonesia
Cite this article:

Nurhayati E, Lesmana CBJ, Aryani LNA. Correlation of religiosity and emotional intelligence among students of Madrasah Aliyah Denpasar. Journal of Clinical and Cultural Psychiatry. 202I;2(I):4-6.

DOI: I0.36444/jccp.v2il .20

Corresponding author: Dr. dr. Cokorda Bagus Jaya Lesmana, SpKJ.

Department of Psychiatry, Faculty of Medicine, Udayana University Jl. Kesehatan I, Denpasar 80I I4 Bali, Indonesia

Email: cokordabagus@unud.ac.id

\begin{abstract}
Background: Emotional intelligence is the ability to feel and understand more effectively against emotional sensitivity that includes the ability to motivate oneself or others, self-control, able to understand the feelings of others effectively and able to manage emotions that can be used to guide the mind to make the best decisions. Religiosity is an understanding of religion in a person that is seen through a person's knowledge and beliefs about his religion and is carried out in worship activities. This study aims to determine the correlation between the level of religiosity and emotional intelligence in students of Madrasah Aliyah (MA) in Denpasar.

Material and Methods: The participant of this research amounted to 90 students of MA in Denpasar. This study used an observational analytic study with design of cross- sectional study. Measuring the level of religiosity using the scale of Religiosity from Glock \& Stark that has been modified in Islam and emotional intelligence is measured using the Emotional Competency Inventory (ECI) scale with a Likert model. Data was analyzed using the SPSS 25.0 program.

Results: Level of religiosity $67 \%$ with high category and $32,2 \%$ with medium category. Emotional intelligence $18,9 \%$ with high category and $81,1 \%$ with medium category. There is significant mild positive correlation between religiosity and emotional intelligence $(r=0.272 ; p=0.010)$.

Conclusion: There is a significant positive mild correlation between the level of religiosity with emotional intelligence.
\end{abstract}

Keywords: cross-sectional studies, Islam, motivation, emotional intelligence

\section{Introduction}

A latest view that develops says that there are other intelligences outside of intellectual intelligence, such as talent, sharpness of social observation, social relations, emotional maturity also have to developed. One of these intelligences, the emotional intelligence which is an important part for every individual to achieve success in life. ${ }^{1}$

Religiosity is a condition that exists in an individual that drive them to behave in daily life according to the degree of obedience to their religion or faith. Religion can be used as a resource for certain emotion, and can support emotional wellness. In addition, religion beliefs and practices have been linked with various emotional control. ${ }^{2}$ Religious individuals can increase their emotion awareness, and their emotional control skill increase. ${ }^{3}$ This religious culture also influences the emotional intelligence of each individual besides spiritual intelligence. ${ }^{4}$

Emotional intelligence is an advantage that each individual has to motivate themselves, resilience in the face of failure, control emotions and delay gratification, and controlling state of their soul. Emotional intelligence can be owned by every person with learning process by experience in their life. Emotional intelligence can be influenced by family factors and non-family factors. ${ }^{2,5}$ One of the non-family factors is learning through formal education. Madrasah Aliyah (MA) is a formal education at the level of a high school based on religion with a proportion of the curriculum with $70 \%$ general knowledge and 30\% with religion knowledge with the application of religious education in worship activities at school. ${ }^{3-5}$ This study aims to determine the correlation between the level of religiosity and emotional intelligence in students of Madrasah Aliyah (MA) in Denpasar. 


\section{Material and Methods}

This study uses an observational analytic study with a cross-sectional study design, to determine the relationship between the level of religiosity and emotional intelligence in MA students in Denpasar City. The main method used in this study was survey subjects using a questionnaire without any treatment. The selection of subjects was done by purposive sampling.

The research subjects were MA students in Denpasar City who met the specified inclusion and exclusion criteria. The questionnaire contained an informed consent sheet, a scale of religiosity, a scale of emotional intelligence. Respondents who gave their written consent then completed the questionnaire and returned it to the researcher.

The measurement for level of religiosity uses the scale of religiosity of Glock \& Stark which has been modified in accordance with the Islamic religion. 17 This scale contains 50 questions that consists of two groups of statements that are favorable (supporting statements) and 25 statement items that are unfavorable (not supporting statements). The total value of all items is obtained using the Likert scale. Item validity coefficients range from 0.303 to 0.655 and Cronbach Alpha reliability coefficient of 0.920 .20

Emotional intelligence is measured using the Emotional Competency Inventory (ECI) scale with a Likert model. The number of items in this scale are 40 items, consisting of 20 favorable items and 20 unfavorable items. The validation coefficient ranges from 0.332 to 0.665 and the reliability coefficient of the Cronbach Alpha value of 0.893 .

Data were analyzed with the SPSS 25.0. A p-value of $<0.05$ was considered significant. This study has obtained information on ethical eligibility from the Research Ethics Commission of the Faculty of Medicine of Udayana University and Sanglah Central General Hospital.

\section{Results}

A total of 90 samples met the inclusion criteria and were included in the data analysis. The characteristics of the research sample are presented in Table 1 . The average age is 16.65 years with the youngest age 15 years and the oldest age is 19 years. The results of the Religiosity Level scale category showed about 29 students included in moderate religiosity level (32.2\%) and 61 students included in High Religiosity Level (67.8\%). The Emotional Intelligence Scale showed that 73 students included in Moderate Emotional Intelligence $(81.1 \%)$ and 17 students included in High Emotional Intelligence (18.9\%).A significant relationship was found between family function and depression in palliative patients at Sanglah Hospital Denpasar $(\mathrm{p}=0.047)$.
Table 1. Subject Characteristics

\begin{tabular}{lcc}
\hline \multicolumn{1}{c}{ Characteristics } & $\mathbf{N}=\mathbf{9 0}$ & $\%$ \\
\hline Age (years), mean \pm SD & $16.65 \pm 0.08$ & N/A \\
\hline Age groups (years) & 3 & \\
15 & 35 & 3.3 \\
16 & 38 & 38.5 \\
17 & 13 & 42.2 \\
18 & & 14.4 \\
\hline Religiosity level* & 0 & \\
Low (<100) & 29 & 0 \\
Moderate $(101-150)$ & 61 & 32.2 \\
High $(>150)$ & & 67.8 \\
\hline Emotional intelligence ${ }^{* *}$ & 0 & 0 \\
Low $(<80)$ & 73 & 81.1 \\
Moderate $(81-120)$ & 17 & 18.9 \\
High $(>120)$ &
\end{tabular}

Table 2. Relationship between religiosity level variables with emotional intelligence

\begin{tabular}{lcc}
\hline \multicolumn{1}{c}{ Variables } & $\mathbf{r}$ & $\mathbf{p}$ \\
\hline $\begin{array}{l}\text { Religiosity level } \\
\text { Emotional intelligence }\end{array}$ & 0.272 & 0.010 \\
\hline \multicolumn{2}{c}{$\mathrm{r}=$ Spearman's correlation coefficient }
\end{tabular}

The relationship of religiosity level variables with emotional intelligence was analyzed by the Spearman correlation test because of the abnormal distribution of data. The Spearman's correlation test produces the Spearman correlation coefficient (r) between the Level of Religiosity and Emotional Intelligence showed mild relationship $(\mathrm{r}=0.272, \mathrm{p}=0.010)$.

\section{Discussion}

The sample in this study had a high level of religiosity in the category of $67.8 \%$. These results indicate that the sample is very good in understanding the lessons of their religion, so that their behavior that is raised is in accordance with the teachings of their religion. ${ }^{1-3}$ This is also because the education system in the MA not only learns about general knowledge, but also religious knowledge accompanied by the application or implementation in daily life.

The sample in this study had a high emotional intelligence was $18.9 \%$ and the moderate category was $81.1 \%$. Most MA students have moderate emotional intelligence, this can be due to other factors that influence emotional intelligence in addition to the level of religiosity, including family environment factors, namely the role of parents and parenting which greatly affects a person's personality and environmental factors non-family that is the community, peers, where adolescence is a period of more interaction with this non-family environment. ${ }^{1-2,6}$

The results of the analysis of the relationship between the level of religiosity with emotional intelligence of the students of Madrasah Aliyah in Denpasar City, found a significant relationship between the level of religiosity with emotional intelligence. their emotional intelligence. ${ }^{7}$ 
The higher the level of student religiosity, the higher the emotional intelligence. The positive relationship between the level of religiosity and emotional intelligence is supported by previous research. Someone who applied religiosity in their daily life will increasing their emotional intelligence.7

Many correlational, longitudinal and experimental studies have shown that religious understanding and appreciation can encourage self-control, self-regulation, emotional regulation and behavioral control which are components of emotional intelligence.8-11 Religiosity has a significant impact on selfcontrol and self-regulation with the ability to recognize one's own emotions or others so that they can establish good interactions with others, it is a component of emotional intelligence. The concept of emotional intelligence is theoretically and empirically linked to emotional well-being, mental health and similar life satisfaction. 12

This study has limitations, which is influencing factors Emotional intelligence has not all been included in research. This research is only in religion-based schools, it would be better if compared between public schools not based on religion in public schools, private schools or international schools. In future studies it is recommended to do a repeat validity test to find out the validity of the sample population accurately.

\section{Conclusion}

There is a significant positive mild correlation between the level of religiosity with emotional intelligence. The higher the level of student religiosity, the higher the emotional intelligence and vice versa. In future studies, it is recommended to do research by linking other variables, because there are still many factors that can be explored related to the level of religiosity and emotional intelligence.

\section{Acknowledgment}

The authors report no conflict of interests.

\section{References}

1. Salovey P, Mayer JD. Emotional Intelligence as A Standard Intelligence. Emotion. 2001; 3(1):232-242.

2. Bar-On R. The Bar-On Model of Emotional-Social Intelligence. Psicothema. 2006;3:1-29.

3. Stein SJ. Emotional Intelligence. Mississauga: John Wiley \& Sons Canada; 2009.

4. Abu-Raiya H. Working with religious Muslim clients: A dynamic, Qura'nic-based model of psychotherapy. Spirituality in Clinical Practice. 2015;2:120.

5. Situmorang SSD. Experiences Learning Strategy for the Development of Religious Teen. Insancita. 2018;3:1-3.

6. Lowicki P, Zajenkowski M. Divine Emotions: On the Link Between Emotional Intelligence and Religious Belief. Journal Religiousity Health. 2017;56:1998-2009.

7. Aslani K, Derikvandi N, Dehghani Y. Relationship between parenting styles, religiosity, and emotional intelligence with addiction potential in high school students. Fundamentals of Mental Health. 2015;17:74-80.

8. El-Menouar Y. The Five dimensions of Muslim Religiosity: Result of an Empirical Study. Methods Data Analyses. 2014;8(1):53-78.

9. Husain SA. Religion and Mental Health from the Moslem Perspective. In: Handbook of Religion and Mental Health (Ed: Koenig HG). Orlando, Florida: Academic Press; 2008, pp. 279-290.

10. Salem MO, Foskett J. Religion and religious experiences. In: Spirituality and Psychiatry (Eds: Cook C, Powell A, Sims A). London: RCPsych Publication; 2009, pp. 233-253.

11. Nesami MB, Goudarzian AH, Zarei H. The Relationship Between Emotional Intelligence with Religious Coping in General Health of Student. Materia Socio Medica. 2015;27(6):412.

12. Copestake S, Gray NS, Snowden RJ. Emotional Intelligence and Psychopathy: A Comparison of Trait and Ability Measures. Emotion. 2013;13(4):691-702. 